\title{
Pandemic Awareness Scale (PAS): Evidence of Validity and Reliability in a Turkish Sample During the COVID-19 Pandemic
}

\author{
Ibrahim Arpaci ${ }^{1}\left(\mathbb{D} \cdot\right.$ Mihyeon Seong $^{2}$ (D) Kasım Karataş ${ }^{3}(\mathbb{D}$
}

Accepted: 11 October 2021/Published online: 17 October 2021

(C) Associação Brasileira de Psicologia 2021

\begin{abstract}
Public awareness is crucial in the prevention and management of the pandemic outbreaks. Accordingly, this study aimed to develop a scale that measures individuals' awareness on pandemic outbreaks. The study investigated psychometric properties of the Pandemic Awareness Scale (PAS) in a Turkish sample $(n=1303)$ during the COVID-19 pandemic. The exploratory-factor-analysis (EFA) results $(n=903)$ indicated a high internal consistency reliability $(\alpha=.89)$ and suggested one-factor structure. The factor structure was confirmed in a different sample $(n=400)$ by a confirmatory-factor-analysis (CFA). The CFA results indicated that the one-factor model fits the data well $\left(x^{2} / \mathrm{df}=3.79, \mathrm{GFI}=.96, \mathrm{IFI}=.97, \mathrm{TLI}=.94, \mathrm{CFI}=.97\right.$, RMSEA =.084). The results suggested that the PAS is a valid and reliable tool to measure Turkish individuals' pandemic awareness level.
\end{abstract}

Keywords Awareness · COVID-19 · Pandemic · Pandemic Awareness Scale · Scale development

Ibrahim Arpaci

iarpaci@bandirma.edu.tr

Mihyeon Seong

mihyeon0624@cs.ac.kr

Kasım Karataş

kasimkaratas@kmu.edu.tr

1 Department of Software Engineering, Bandirma Onyedi Eylul University, 10200 Balıkesir, Turkey

2 Department of Nursing, Chang Shin University, Changwon-si, Gyeongsangnam-do, Republic of Korea

3 Department of Educational Sciences, Karamanoglu Mehmetbey University, Karaman, Turkey 


\section{Introduction}

In the aftermath of the global threat of H1N1 influenza (swine flu) in 2009, health ministries across the world have devised a number of control measures for the pandemic and prevent its spread (Watkins, 2020). Furthermore, severe acute respiratory syndrome (SARS) in 2002, Ebola during the 2013 to 2016, and ZIKA in 2015 affected a large proportion of the population. Nevertheless, with the novel coronavirus (COVID-19) pandemic in 2019, the number of deaths has increased significantly in many countries. Pandemics have been affecting the world in several aspects, including psychological, social, political, and economic effects (WHO, 2020; Wu \& McGoogan, 2020). Therefore, in response to COVID-19, many countries are currently taking preventive measures for public health by encouraging handwashing, social distancing, and postponing or canceling large public meetings (Bedford et al., 2020). However, uncertain prognosis, lack of resources for screening and treatment, and unfamiliar public health measures that violate individuals' freedom are causing anxiety and widespread emotional distress (Pfefferbaum \& North, 2020). This global pandemic has brought a great social impact to the point of separating history into the times before and after the coronavirus, suggesting the need for attention and preparation for new infectious diseases that can occur at any time (Friedman, 2020).

According to previous studies, people are more concerned about COVID-19 than seasonal influenza (Morning Consult, 2020). In fact, they fear contact with potentially infected individuals, which intensifies fear globally, leading to psychosocial problems, such as stigma and discrimination (Lin, 2020; Pappas et al., 2009). As such, fear can amplify the damage of the disease itself (Ahorsu et al., 2020), but the focus has primarily been on vaccine development and infection control as a response to COVID-19 worldwide (Wang et al., 2020). Whereas psychosocial aspects were not being considered, and therefore, more research is urgently needed to address this issue and improve people's behavior by rushing to correct the current situation.

It is important to conduct as much research as possible on public concerns, knowledge, attitudes, and behaviors during an epidemic outbreak (Balkhy et al., 2010). The recognition of diseases by the public leads to subjective thoughts and feelings about diseases being formed based on general knowledge and personal experiences on diseases acquired in the healthcare environment.

According to Leventhal's common sense model of self-regulation, the way to cope with a disease can vary depending on the characteristics of recognizing a disease. Thus, the physical and psychological health status can be changed (Leventhal et al., 2003). In particular, epidemics are highly contagious; therefore, it is important to improve communication skills between public health officials, clinicians, and people (Balkhy et al., 2010). Clinical preparation for infectious diseases and highly pathogenic viruses requires the ability to predict individual awareness (Almutairi et al., 2015). Strategies for the raising awareness on pandemics are essential and can work effectively in controlling pandemics (Shilpa et al., 2014).

However, currently, it is difficult to find a tool to evaluate public awareness specialized in various pandemics, including COVID-19. Most of the current 
literature evaluated perceptions through measuring disease recognition tools or knowledge, attitudes, and behaviors. Therefore, this study aims to contribute to the literature of evidence-based public health practices by developing and testing a scale that can measure individuals' awareness on pandemic outbreaks (namely Pandemic Awareness Scale, PAS (Appendix)). This study may contribute the quality of public health in preparing effective prevention strategies by identifying individuals' understanding of the pandemic and predicting human behavior.

\section{Theoretical Background}

Awareness can be defined as a summation of thoughts, opinions, and propositions established and checked as a possible accurate response to objective reality; it is a social product in its essence (Kim \& Nam, 2015). Awareness can influence attitudes according to accurate information or knowledge and induce new motivations by changing attitudes (Cornforth, 1963).

Through awareness, people have historically gained knowledge on the objective world of nature and society. Based on this achievement, they act on the objective world to make changes. Beyond the intellectual satisfaction of simply knowing the objectified world, it contributes to human practices and real life (Arpaci, 2021). In addition, psychology includes all mental experiences, such as sensations, perceptions, emotions, representations, chastity, and motivation; and the perception of an object always indicates that the essence of the object is grasped (Cornforth, 1963).

Awareness of health refers to displaying personal opinions on health conditions that cannot be measured by medical methods, by subjectively making a comprehensive evaluation of physical, psychological, and social aspects of health conditions (Choi, 2008). In particular, awareness of a disease indicates that the subject recognizes the threat of a disease through various information and symptoms; it refers to the factual and empirical awareness, in that, the subject knows about the disease (Hopman \& Rijken, 2015). Connelly et al. (1989) argued that subjectively perceived health is sensitive to mental and psychological stress; thus, high stress and low well-being deteriorate the quality of life and show symptoms of disease even in healthy people. In addition, the awareness regarding diseases is gaining importance not only because of how individuals perceive these diseases but also because of its practical impact on individuals' health (Choi et al., 2016).

From the $2009 \mathrm{H} 1 \mathrm{~N} 1$ experience, we learned to prepare for and identify the impact of a public health emergency (Stoto, 2012). To reduce confusion about the epidemic of infectious diseases, an approach that can provide correct knowledge and awareness is needed (Park \& Kim, 2010). Therefore, in this study, a self-report scale was developed to measure individuals' awareness on pandemic outbreaks and its psychometric properties were tested. 


\section{Method}

The sequential approach followed by the study during the scale development included nine steps: (1) define theoretical background of the constructs, (2) generate scale items, (3) assess content validity through expert panel reviews, (4) pilot study, (5) collect data for the first study, (6) conduct an exploratory factor analysis, (7) refine the scale and items, (8) collect data for the second study, (9) and conduct a confirmatory analysis. The study I included the first seven steps, and the study II consisted of the remaining two steps.

\section{Study I}

\section{Content Validity}

Awareness theory was used as a theoretical background during the development of the scale items. The initial item pool consisted of 37 items, which measure individuals' awareness level about pandemic outbreaks. Content validity of the scale items was examined by four experts (two professors in educational sciences and two professors in health sciences). Expert panel reviewed the items and rated them between one and ten. Items scored more than eight in average were remained, whereas 21 items scored lower than eight over ten, and therefore, they were eliminated. Thereby, the 18-item initial form was obtained. A pilot test was conducted on the initial item pool to establish a preliminary version of the scale. A focus group of 35 participants (15 females and 20 males, ranging in age from 17 to 55 years, with a mean age of 27.4 years) was recruited for the pilot test. Based on the feedbacks obtained from focus group interviews, the statements were revised. Furthermore, based on the results of item analysis, two items that yielded item-total correlations lower than 0.40 were discarded, resulting in a 16 -item preliminary version of the scale.

\section{Sample and Procedure}

The preliminary 16-item scale was administered to a sample of 903 Turkish participants (604 female and 299 male) with a mean age of 27.27 years \pm 12.16 (ranged between 14 and 82). A considerable percentage of the participants (55.3\%) were aged between 19 and 24 years. The rest of the respondents were aged between 13 and 18 years (9.7\%), 25 and 35 years (14.5\%), and over 35 years $(20.5 \%)$. An online instrument prepared by Google Forms was used to collect. All the questions in the survey were mandatory; thereby, there was no data missing data. The samples were informed consent and free not to participate in this study. Results showed that $70.9 \%$ of them were single. Furthermore, $16.6 \%$ of the participants were smokers. Table 1 indicates that $9.2 \%$ of the sample have a chronic disease (i.e., asthma, diabetes, thyroid, hypertension, cancer, or cardiovascular disease) and $9.6 \%$ of them have been continuously using a drug. About $7 \%$ of the participants were infected 
Table 1 Descriptive statistics of the participants

\begin{tabular}{llll}
\hline & & Frequency & Percent \\
\hline Marital status & Married & 263 & 29.1 \\
Education level & Single & 640 & 70.9 \\
& Uneducated & 9 & 1 \\
& Primary school & 58 & 6.4 \\
& Secondary school & 44 & 4.9 \\
& High school & 184 & 20.4 \\
Smoker & Vocational high school & 82 & 9.1 \\
& Undergraduate & 503 & 55.7 \\
Chronic disease & MSc/PhD & 23 & 2.5 \\
& Yes & 150 & 16.6 \\
Use a drug & No & 753 & 83.4 \\
COVID-19 infection & Yes & 83 & 9.2 \\
COVID-19-infected first-degree relative & No & 820 & 90.8 \\
& Yes & 87 & 9.6 \\
Death of any relative from COVID-19 & Negative & 816 & 90.4
\end{tabular}

with COVID-19, whereas $53.6 \%$ of the participants had a first-degree relative (i.e., parent, child, or sibling) infected with COVID-19 and about $10 \%$ of them lost their relatives from COVID-19.

\section{Exploratory Factor Analysis}

The EFA using principal component with varimax rotation was conducted in SPSS (ver. 23) to identify factor structure of the Pandemic Awareness Scale (PAS). In the initial run, three factors were identified (eigenvalues $>1.0$ ) that together accounted for $57.32 \%$ of the total variance. However, four items were excluded since they either loaded more than a single factor or had a factor load less than 0.40. Furthermore, three items were removed since they had communalities less than 0.30 . The final run based on the remaining nine items resulted in a one-factor solution. The single factor had an eigenvalue of 5.13 and accounted for $56.995 \%$ of the variance. Kaiser's measure-of-sampling-adequacy was 0.903 . Bartlett's test results suggested the values were significant $\left(\chi^{2}(\mathrm{df}=36)=4683.446, p<0.001\right)$ and all items had factor loadings higher than the threshold value of 0.40 . Furthermore, reliability analysis results indicated that the nine-item scale showed a good internal consistency reliability with a Cronbach's alpha value of 0.894 . Furthermore, the correlation between each item was significant at the 0.01 level. Finally, a Kolmogorov-Smirnov 
test indicated that the data do not follow a normal distribution, $\mathrm{D}(903)=0.284$, $p<0.001$. Table 2 shows the communalities, factor loadings for principal components with varimax rotation, and reliability analysis results.

\section{Item Analysis}

The extreme group comparison method was used to compare the difference between the total scores of the highest $27 \%$ and the lowest $27 \%$. The "independent sample $t$-test" results revealed that there is a significant difference in the total scores between the lowest $27 \%(\mathrm{M}=36.76, \mathrm{SD}=6.03, \mathrm{SE}=0.386)$ and the highest $27 \%(\mathrm{M}=45.00$, $\mathrm{SD}=0.00, \mathrm{SE}=0.00)$ groups $(t(\mathrm{df}=484)=21.275, p<0.001)$. This suggested that the PAS can significantly differentiate the highest and lowest groups.

\section{Gender and Age Differences}

The study investigated statistical differences in the total score of the PAS between male $(n=299)$ and female $(n=604)$ participants. The "independent sample $t$-test" results indicated that the pandemic awareness were significantly different between male $(\mathrm{M}=41.12, \mathrm{SD}=5.53)$ and female $(\mathrm{M}=42.93, \mathrm{SD}=4.05)$ participants $t(901)=5.596, p<0.001$. Furthermore, age differences were investigated in the total score of the PAS among young adults (13-18), adults (19-34), and older adults (over 35). The "one way ANOVA" results indicated that the pandemic awareness were not significantly different among the age groups $F(2)=1.93, p=0.146$.

\section{Study II}

\section{Sample}

The nine-item scale was administered to a different sample of 400 Turkish participants (253 female and 147 male) with a mean age of 24.61 years \pm 9.83 (ranged between 13 and 76). A considerable percentage of the respondents (62.7\%) were aged between 19 and 24 years. The rest of the respondents were aged between 13 and 18 years (12.5\%), 25 and 35 years (11.8\%) and over 35 years (13\%). About $63 \%$ of the participants were undergraduates and $77 \%$ of them were single. Furthermore, $16 \%$ of the participants were smokers. About $7.5 \%$ of the participants had a chronic disease (i.e., asthma, diabetes, thyroid, hypertension, cancer, or cardiovascular disease), and therefore, they have been continuously using a drug. About $9 \%$ of the participants were infected with COVID-19, whereas $58 \%$ of the participants had a firstdegree relative (i.e., parent, child, or sibling) infected with COVID-19 and $11.3 \%$ of them lost their relatives from COVID-19.

The second administration to the sample of 400 participants was conducted after 3 weeks of the first administration. The main purpose of the second administration was to investigate test-retest reliability. The correlation analysis results of the two administrations indicated a test-retest reliability estimate of 0.87 . These results indicated that the nine-item scale has a high temporal stability and internal consistency. 


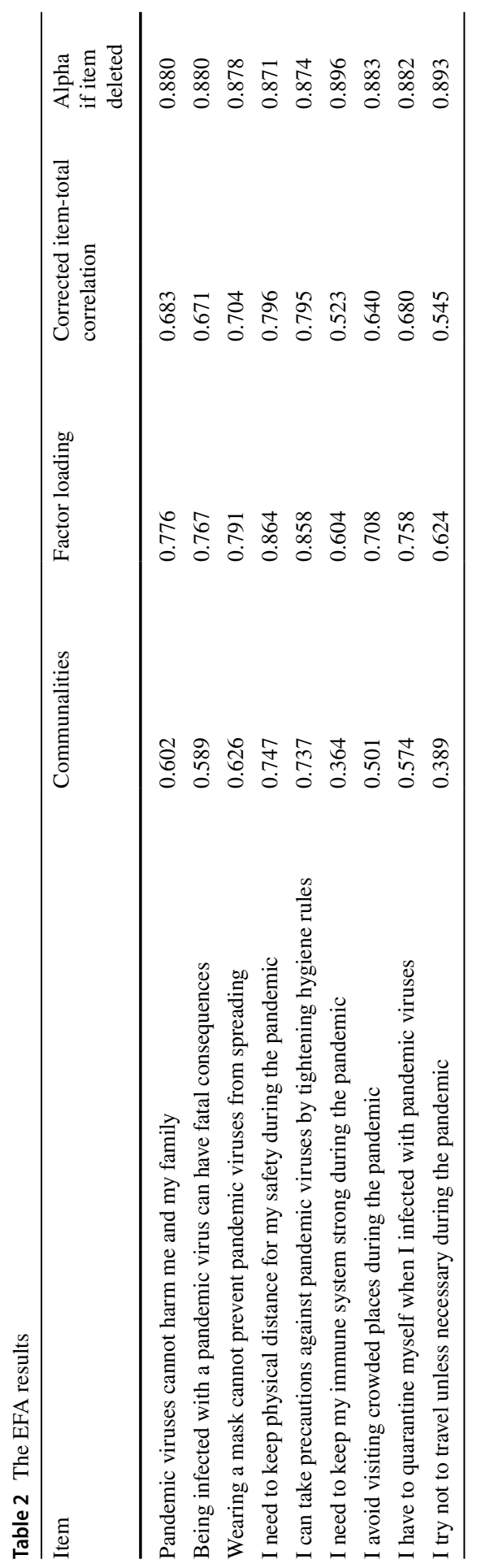




\section{Confirmatory Factor Analysis}

CFA was performed by using SPSS AMOS (ver. 23) to assess the measurement model. According to the threshold values suggested by Kline (2005), model fit estimates indicated a good fit between the measurement model and data: $\left(x^{2}(\mathrm{DF}=19)=71.964, \quad x^{2} / \mathrm{df}=3.788, \quad \mathrm{GFI}=0.964, \quad \mathrm{AGFI}=0.914, \quad \mathrm{NFI}=0.957\right.$, $\mathrm{IFI}=0.968, \quad \mathrm{TLI}=0.938, \quad \mathrm{CFI}=0.968, \quad \mathrm{SRMR}=0.034, \quad \mathrm{RMSEA}=0.084$ $\mathrm{LO} 90=0.064$, HI90 $=0.105)$. The results indicated that single-factor structure model showed a good fit with the data. Table 3 shows the maximum likelihood estimates of the one-factor model.

\section{Discussion and Conclusion}

COVID-19 negatively affected people psychologically (Akat \& Karataş, 2020). Many psychometric scales have been developed to determine the negative psychological effects (fear, phobia, stress, anxiety, etc.) of COVID-19 on humans (Ahorsu et al., 2020; Arpaci et al., 2020, 2021; Haktanir et al., 2020; Lee, 2020; Taylor et al., 2020). The prominent features of these scales were that they were specific to COVID-19. However, the Pandemic Awareness Scale (PAS) developed in this research has an advantage in terms of determining the level of awareness on pandemic outbreaks in general.

Since the last quarter of 2019, almost the only agenda in the world is the COVID-19 pandemic. Most of the people living in the world have just met the pandemic fact. Basically, pandemics have arisen from time to time throughout history and have ravaged humanity. Recently, severe acute respiratory syndrome (SARS), Ebola outbreak, swine flu or H1N1/09 pandemic, and ZIKA infectious diseases have had profound and lasting effects on societies (Huremović, 2019). Presumably, the COVID-19 pandemic is also predicted to be not the last pandemic (Dey et al., 2020; Khanna et al., 2020). In this respect, people need to be

Table 3 The CFA results

\begin{tabular}{lllll}
\hline Item & $\begin{array}{l}\text { Standardized } \\
\text { estimate }\end{array}$ & Standard error & Critical ratio & $P$ \\
\hline Item 1 & 0.644 & 0.073 & 11.432 & $* * *$ \\
Item 2 & 0.738 & 0.093 & 13.260 & $* * *$ \\
Item 3 & 0.687 & 0.093 & 12.550 & $* * *$ \\
Item 4 & 0.705 & 0.087 & 12.372 & $* * *$ \\
Item 5 & 0.772 & 0.091 & 13.789 & $* * *$ \\
Item 6 & 0.593 & 0.124 & 10.880 & $* * *$ \\
Item 7 & 0.690 & 0.114 & 12.538 & $* * *$ \\
Item 8 & 0.706 & 0.081 & 0.10 .705 & $* * *$ \\
Item 9 & 0.585 & 0.108 & 10.705 & $* * *$ \\
\hline$* * * p<0.001$ & & &
\end{tabular}


aware of the pandemic and take the necessary precautions. Likewise, it is necessary to increase awareness level of people about how the virus that causes the pandemic is transmitted.

Balkhy et al. (2010) found that people who are not aware of the pandemic experience high anxiety. Labban et al. (2020) reported that individuals with low COVID-19 awareness levels did not take adequate measures to protect themselves from the virus. Alahdal et al. (2020) conducted a study to determine the COVID19 awareness level; of all the participants, 58\% showed a moderate level of awareness. In addition, a positive correlation is resulted between the awareness level of the participants and taking the necessary practices to protect against COVID-19. Tripathi et al. (2020) highlighted to improve awareness in general population and to protect preventative practices from COVID-19. Common discourse in the past and current studies on the pandemic is that public awareness must be improved to be prepared for epidemic and pandemic situations. Otherwise, the social and psychological damage caused by epidemics on people continues unabated. In this respect, the PAS is considered to have important contributions in the literature by determining the individuals' awareness on pandemic outbreaks. Since pandemic is a universal catastrophe, the researchers suggested adaptation studies of the PAS to different languages. Likewise, psychological and sociological factors that may affect awareness on pandemic outbreaks can be determined.

In conclusion, the findings indicated that the PAS is a valid and reliable tool to measure Turkish individuals' pandemic awareness level. The findings also indicated that the pandemic awareness level were higher among female than male participants. By introducing a new measurement scale, the present study constitutes a step forward in the assessment of pandemic awareness and opens up some interesting avenues for future investigation. However, there are some certain limitations of the study. The scale items more emphasis on behavioral dimension of the awareness than knowledge and emotion-related dimensions. Furthermore, concurrent validity study was not conducted in this scale development process since there was not a well-established measure for the pandemic awareness.

\section{Appendix}

\section{Pandemic Awareness Scale (PAS)}

1. Pandemic viruses cannot harm me and my family (R: Reverse-scored item).

2. Being infected with a pandemic virus can have fatal consequences.

3. Wearing a mask cannot prevent pandemic viruses from spreading (R).

4. I need to keep physical distance for my safety during the pandemic.

5. I can take precautions against pandemic viruses by tightening hygiene rules.

6. I need to keep my immune system strong during the pandemic.

7. I avoid visiting crowded places during the pandemic.

8. I have to quarantine myself when I infected with pandemic viruses. 
9. I try not to travel unless necessary during the pandemic.

Scoring: The PAS (single-factor) has nine items scored on a five-point Likerttype scale ranged from "strongly disagree (1)" to "strongly agree (5)." Total score ranges between 9 to 45 and a higher score reflects a higher level of awareness on pandemic outbreaks.

Data Availability Data will be available upon request.

\section{Declarations}

Consent to Participate Informed consent was obtained from all individual participants included in the studies.

Conflict of Interest The authors declare no competing interests.

\section{References}

Ahorsu, D. K., Lin, C. Y., Imani, V., Saffari, M., Griffiths, M. D., \& Pakpour, A. H. (2020). The fear of COVID-19 scale: Development and initial validation. International Journal of Mental Health and Addiction. https://doi.org/10.1007/s11469-020-00270-8

Akat, M., \& Karataş, K. (2020). Psychological effects of COVID-19 pandemic on society and its reflections on education. Turkish Studies, 15(4), 1-13. https://doi.org/10.7827/TurkishStudies. 44336

Alahdal, H., Basingab, F., \& Alotaibi, R. (2020). An analytical study on the awareness, attitude and practice during the COVID-19 pandemic in Riyadh, Saudi Arabia. Journal of Infection and Public Health, 13(10), 1446-1452. https://doi.org/10.1016/j.jiph.2020.06.015

Almutairi, K. M., Al Helih, E. M., Moussa, M., Boshaiqah, A. E., Saleh Alajilan, A., Vinluan, J. M., \& Almutairi, A. (2015). Awareness, attitudes, and practices related to coronavirus pandemic among public in Saudi Arabia. Family \& Community Health, 38(4), 332-340. https://doi.org/10.1097/FCH. 0000000000000082

Arpaci, I. (2021). Relationships between early maladaptive schemas and smartphone addiction: The moderating role of mindfulness. International Journal of Mental Health and Addiction, 19(3), 778-792. https://doi.org/10.1007/s11469-019-00186-y

Arpaci, I., Karataş, K., \& Baloğlu, M. (2020). The development and initial tests for the psychometric properties of the COVID-19 Phobia Scale (C19P-S). Personality and Individual Differences, 164, 110108. https://doi.org/10.1016/j.paid.2020.110108

Arpaci, I., Karataş, K., Baloğlu, M., \& Haktanir, A. (2021). COVID-19 phobia in the United States: Validation of the COVID-19 Phobia Scale (C19P-SE). Death Studies. https://doi.org/10.1080/07481187. 2020.1848945

Balkhy, H. H., Abolfotouh, M. A., Al-Hathlool, R. H., \& Al-Jumah, M. A. (2010). Awareness, attitudes, and practices related to the swine influenza pandemic among the Saudi public. BMC Infectious Diseases, 10(1), 42. https://doi.org/10.1186/1471-2334-10-42

Bedford, J., Enria, D., Giesecke, J., Heymann, D. L., Ihekweazu, C., Kobinger, G., et al. (2020). COVID19: Towards controlling of a pandemic. The Lancet, 395(10229), 1015-1018. https://doi.org/10. 1016/S0140-6736(20)30673-5

Choi, S. W. (2008). A study on subjective health perception, daily living ability, and depression of the elderly in hospital use [Master's thesis]. Keimyung University.

Choi, M. G., Yoon, S. S., \& Oh, J. H. (2016). Development and validation of the Korean Illness Perception Questionnaire (K-IPQ). Health Communication, 11(2), 123-143. https://doi.org/10.15715/ kjhcom.2016.11.2.123 
Connelly, J. E., Philbrick, J. T., Smith, G. R. Jr, Kaiser, D. L., \& Wymer, A. (1989). Health perceptions of primary care patients and the influence on health care utilization. Medical Care, 27(3), 99-109. https://doi.org/10.1097/00005650-198903001-00009

Cornforth, M. (1963). The theory of knowledge (3rd ed.). International Publishers Co., Inc.

Dey, S., Cheng, Q., \& Tan, J. (2020). All for one and one for all: Why a pandemic preparedness league of nations? Health Policy and Technology, 9(2), 179-184. https://doi.org/10.1016/j.hlpt.2020.04.009

Friedman, T. L. (2020). Our new historical divide: BC and AC the world before corona and the world after. The New York Times. Retrieved October 13, 2021, from https://www.nytimes.com/2020/03/17/ opinion/coronavirus-trends.html

Haktanir, A., Seki, T., \& Dilmaç, B. (2020). Adaptation and evaluation of Turkish version of the fear of COVID-19 scale. Death Studies. https://doi.org/10.1080/07481187.2020.1773026

Hopman, P., \& Rijken, M. (2015). Illness perceptions of cancer patients: Relationships with illness characteristics and coping. Psycho-Oncology, 24(1), 11-18. https://doi.org/10.1002/pon.3591

Huremović, D. (2019). Brief history of pandemics (Pandemics throughout history). In D. Huremović (Ed.), Psychiatry of pandemics (pp. 7-35). Springer. https://doi.org/10.1007/978-3-030-15346-5_2

Khanna, R. C., Cicinelli, M. V., Gilbert, S. S., Honavar, S. G., \& Murthy, G. S. (2020). COVID 19 pandemic: Lessons learned and future directions. Indian Journal of Ophthalmology, 68(5), 703-710. https://doi.org/10.4103/ijo.IJO_843_20

Labban, L., Thallaj, N., \& Labban, A. (2020). Assessing the level of awareness and knowledge of COVID-19 pandemic among Syrians. Archives of Medicine, 12(2), 8. https://doi.org/10.36648/ 1989-5216.12.2.309

Kim, J. H., \& Nam, Y. S. (2015). Elementary general teacher's complex and subtle recognition and attitude to student with disabilities. The Journal of Inclusive Education, 10(1), 99-119. https://doi.org/ 10.26592/ksie.2015.10.1.99

Kline, R. B. (2005). Principles and practice of structural equation modeling (2nd ed.). Guilford.

Lee, S. A. (2020). The Coronavirus Anxiety Scale: A brief mental health screener for COVID-19 related anxiety. Death Studies, 44(7), 393-401. https://doi.org/10.1080/07481187.2020.1748481

Leventhal, H. L. B. I., Brissette, I., \& Leventhal, E. A. (2003). The common-sense model of self- regulation of health and illness. The Self-Regulation of Health and Illness Behaviour, 1, 42-65.

Lin, C. Y. (2020). Social reaction toward the 2019 novel coronavirus (COVID-19). Social Health and Behavior, 3(1), 1. https://doi.org/10.4103/SHB.SHB_11_20

Morning Consult. (2020). How the coronavirus outbreak is impacting public opinion. Retrieved January 7, 2021 from https://morningconsult.com/

Pappas, G., Kiriaze, I. J., Giannakis, P., \& Falagas, M. E. (2009). Psychosocial consequences of infectious diseases. Clinical Microbiology and Infection, 15(8), 743-747. https://doi.org/10.1111/j.14690691.2009.02947.x

Park, S. Y., \& Kim, M. (2010). Factors affecting children's preventive behaviors for novel influenza A (H1N1). Korean Journal of Health Education and Promotion, 27(1), 9-19.

Pfefferbaum, B., \& North, C. S. (2020). Mental health and the Covid-19 pandemic. New England Journal of Medicine, 383, 510-512. https://doi.org/10.1056/NEJMp2008017

Shilpa, K., Kumar, B. P., Kumar, S. Y., Ugargol, A. R., Naik, V. A., \& Mallapur, M. D. (2014). A study on awareness regarding swine flu (influenza A H1N1) pandemic in an urban community of Karnataka. Medical Journal of Dr. D. Y. Patil University, 7(6), 732-737. https://doi.org/10.4103/09752870.144862

Stoto, M. A. (2012). The effectiveness of US public health surveillance systems for situational awareness during the $2009 \mathrm{H} 1 \mathrm{~N} 1$ pandemic: A retrospective analysis. PLOS ONE, 7(8), e40984. https://doi.org/ 10.1371/journal.pone.0040984

Taylor, S., Landry, C. A., Paluszek, M. M., Fergus, T. A., McKay, D., \& Asmundson, G. J. G. (2020). Development and initial validation of the COVID stress scales. Journal of Anxiety Disorders, 72(4), 102232. https://doi.org/10.1016/j.janxdis.2020.102232

Tripathi, R., Alqahtani, S. S., Albarraq, A. A., Meraya, A. M., Tripathi, P., Banji, D., ... \& Alnakhli, F. M. (2020). Awareness and preparedness of COVID-19 outbreak among healthcare workers and other residents of South-West Saudi Arabia: A cross-sectional survey. Frontiers in Public Health, 8, 482. https://doi.org/10.3389/fpubh.2020.00482

Wang, D., Hu, B., Hu, C., Zhu, F., Liu, X., Zhang, J., ... \& Peng, Z. (2020). Clinical characteristics of 138 hospitalized patients with 2019 novel coronavirus-infected pneumonia in Wuhan, China. Jama, 323(11), 1061-1069. https://doi.org/10.1001/jama.2020.1585 
Watkins, J. (2020). Preventing a COVID-19 pandemic. BMJ, 368, m810. https://doi.org/10.1136/bmj. m810

World Health Organization (WHO). (2020, August 23). Coronavirus disease (COVID-19): Weekly epidemiological update. https://apps.who.int/

Wu, Z., \& McGoogan, J. M. (2020). Characteristics of and important lessons from the coronavirus disease 2019 (COVID-19) outbreak in China: Summary of a report of 72314 cases from the Chinese Center for Disease Control and Prevention. JAMA, 323(13), 1239-1242. https://doi.org/10.1001/ jama.2020.2648 